\title{
A Methodological Approach to Evaluate Structural Building Projects Through the Environmental Economic Index
}

José Manuel Romo Orozco

Universidad Autonoma de San Luis Potosi

Julio Contreras

Universidad Autonoma de San Luis Potosi

José Ramón Corona Armenta

Universidad Autonoma del Estado de Hidalgo

Luis Fernando Morales Mendoza ( $\nabla$ fernando.morales@correo.uady.mx )

Universidad Autonoma de Yucatan https://orcid.org/0000-0003-1747-6454

\section{Research Article}

Keywords: Building, performance, parametric evaluation, environmental impacts

Posted Date: June 1st, 2021

DOI: https://doi.org/10.21203/rs.3.rs-359400/v1

License: (c) (i) This work is licensed under a Creative Commons Attribution 4.0 International License. Read Full License 


\title{
A methodological approach to evaluate structural building projects through the Environmental Economic Index
}

Authors: José Manuel Romo Orozco a, Julio César Contreras Jiménez ${ }^{\mathrm{b}}$, José Ramón Corona Armenta ${ }^{\mathrm{c}}$, Luis Fernando Morales-Mendoza ${ }^{\mathrm{d}}$

a Unidad Académica Multidisciplinaria Zona Media, Universidad Autónoma de San Luis Potosí, San Luis Potosí, México. jmromo@uaslp.mx

Carretera San Ciro Km 4, El Carmen, Rioverde, San Luis Potosí, México. CP. 79615

b Unidad Académica Multidisciplinaria Zona Media, Universidad Autónoma de San Luis Potosí, San Luis Potosí, México. julio.contreras@uaslp.mx

Carretera San Ciro Km 4, El Carmen, Rioverde, San Luis Potosí, México. CP. 79615

c Universidad Autónoma del Estado de Hidalgo, Instituto de Ciencias Básicas e Ingeniería

Carretera Pachuca - Actopan Km. 4.5, Campo de Tiro, 42039 Pachuca de Soto, Hidalgo.

d Universidad Autónoma de Yucatán, Facultad de Ingeniería Química

Periférico Norte kilómetro 33.5, C.P. 97203, Mérida, Yucatán, México

Corresponding author: Julio César Contreras Jiménez, julio.contreras@uaslp.mx.

\begin{abstract}
The construction industry has a relevant social and economic function and has become fundamental to achieving the Paris Agreement and the United Nations Sustainable Development Goals. This industry contributes significantly to global $\mathrm{CO}_{2}$ emissions due to embodied and operating energy. There are methodologies to evaluate them, but they lack integration with other variables. In the case of buildings and assessing safety and costs, environmental assessment needs to be incorporated; current methodologies are complex to implement and, in general, costly in terms of economic and human resources. This research proposes the Environmental Economic Index (EEI) to evaluate structural building projects and support decisionmaking, obtained from a simplified methodology. In the case study, located in San Luis Potosi, Mexico, the same building structure was designed to subject to different operational loads and lateral forces, with structural concrete and structural steel. For this building, the concrete structure subject to seismic actions had a better result when estimating the EEI and comparing it with the other structural alternatives. The contribution of this work is to develop a simplified methodology to evaluate structural projects in the design phase, which integrates economic, environmental, and safety variables and supports decisionmaking in designers and real estate developers.
\end{abstract}

Keywords: Building, performance, parametric evaluation, environmental impacts

\section{Graphic abstract}

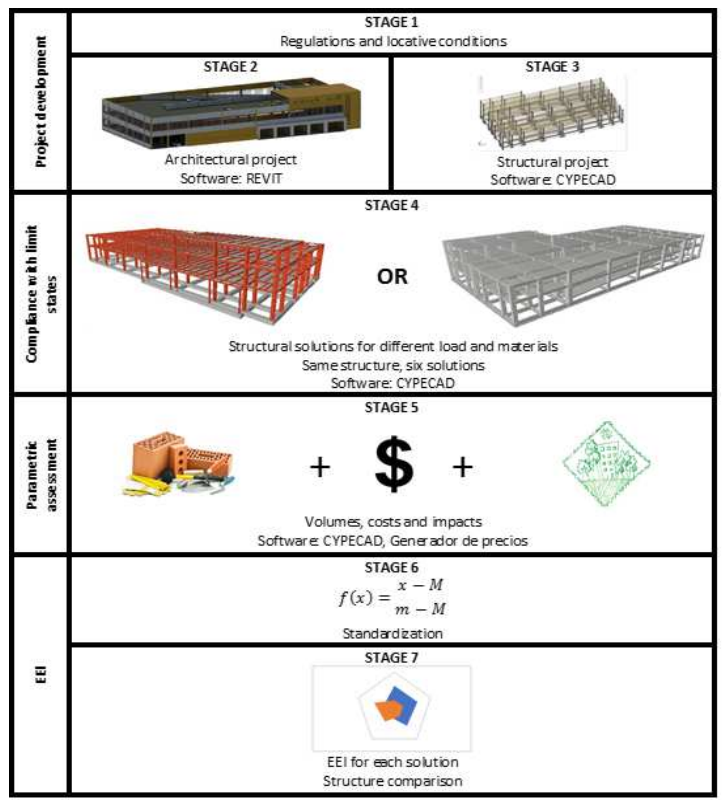




\section{Introduction}

Buildings have a fundamental function for social development. However, the life cycle of a building generates negative externalities such as natural resources and energy, the generation of waste during the construction process, and the building's useful life or infrastructure. In any building, the structure is essential to achieve adequate performance. At the beginning of building design, through good techniques and the materials' properties, the structural project could lead to adequate solutions without compromising its stability a reliable and safe use. Achieving absolute security is a difficult task in structural design because eliminating risks of failure implies high economic costs; there will always be the possibility of failure because their elimination could increase the use of resources to avoid catastrophic events with a low probability during the building life cycle. In any case, the relationship between security and a possible failure of the structure establishes a delicate link with economic, social, and human costs.

Buildings currently account for $28 \%$ of global energy-related $\mathrm{CO}_{2}$ emissions and $39 \%$ of emissions from the construction industry, including; $11 \%$ of building materials such as steel, cement, and glass (GlobalABC/IEA/UNEP 2020a; IEA 2019). Also, indirect emissions, i.e., those related to power generation for electricity and commercial heating, account for most energy-related $\mathrm{CO}_{2}$ emissions in the building sector. Both reports point to the need for urgent action to reverse this trend.

The construction and building industry has become critical to achieving the Paris Agreement and the United Nations (UN) Sustainable Development Goals (SDG) (Goubran and Cucuzzella 2019). However, it is necessary to increase the energy efficiency used in buildings by 3\% each year. Reductions in building emissions represent one-third of the total reductions required to align with the International Energy Agency's (IEA) proposed Sustainable Development Scenario 2. The above aims to achieve the energy-related sustainable development goals of achieving universal access to energy (SDG 7), reducing the severe health impacts of air pollution (part of SDG 3), and addressing climate change (SDG 13) (IEA 2019). The decarbonization of buildings is also in alignment with the goals of SDG 9 to use resources more efficiently through clean and environmentally sound technologies and industrial processes, SDG 12 to ensure sustainable production and consumption patterns, as well as with SDG 11, to support less advanced countries in the construction of sustainable and resilient buildings using local materials (United Nations 2020). The IEA and the Global ABC have developed a series of regional roadmaps to identify region-specific priority actions and pathways, including Latin America (GlobalABC/IEA/UNEP 2020b). Effective policies and regulations are needed that cover the entire life cycle of buildings, including design, development, operation, and end-of-life stages, and also act beyond site boundaries through neighborhood planning and clean energy. Greenhouse gas emissions or energy consumption related to each phase of the life cycle of materials: steel, cement blocks, and non-certified wood are primary sources of $\mathrm{CO}_{2}$ building products.

Globally, population growth and rapid urbanization will require capital investments in infrastructure. By 2060, the total building area will double, and more than $50 \%$ of this area expects to double in the next 20 years (World Green Building Council 2019). Besides, older buildings will require extensive and energy-efficient renovation, which will contribute to increased embodied carbon. Some parts of buildings and infrastructure are typically responsible for most of the added carbon emissions. Building elements, such as foundations and structure, typically represent the most considerable contribution to embodied carbon due to the large volumes of material they use and often contain carbon-intensive structural materials such as concrete, steel, and masonry. Cement and steel manufacturing is responsible for about $14-16 \%$ of global carbon emissions (World Green Building Council 2019). However, recycling and reuse reduce embodied carbon, as steel recycles without losing its physical qualities.

Estimating an entire material, product, or construction project's environmental impacts is key to supporting decision-making to embodied carbon, water, and energy needs. Life Cycle Assessment (LCA) has become a globally accepted method for assessing and communicating these environmental impacts. International standards (ISO 14044 and EN15804) exist for using LCA and communicating the results in Environmental Product Declarations (EPDs). Several national and regional online databases were developed, facilitating the agreement of standard methodologies and application protocols for generating environmental declarations (EPDs) of construction products among participating members and products from the manufacturing sector. In an extensive study of 250 cases applied to LCA in buildings, it was possible to develop LCA models and general rules in this type of complex system (Saade, Guest and Amor 2019).

As for the economic analysis of a building, there are tools such as the Life Cycle Cost (LCC). LCC is a method used to evaluate the expected building economic performance throughout its life cycle: the design and construction of the building, the operation and maintenance of the building, and the costs associated with the building's disposal at the end of its life cycle. There is an international standard (ISO 15686-5:2008) for using LCC, and it provides an orderly structure for breaking down the components of the building's life cycle cost, including 1) cost of design and construction, 2) cost of operation, 3) cost of 
maintenance and 4) end-of-life cost (International Organization for Standardization $2020 \mathrm{a}$, b). However, in the construction sector, LCC implementation remains limited. It faces practical problems such as poor benefit perception by building owners, lack of reliable life cycle cost data, scarcity of information on the actual cost and performance of buildings in use, uncertainty associated with life cycle cost assumptions. In addition to the imperfect understanding of life cycle costing methodology and its application, the following are critical barriers to the widespread application of life cycle costing in the construction sector.

The LCA and LCC can determine the feasibility of repairs in situations without or with flooding that affects the building. Balasbaneh, Bin, and Gohari (2019) studied five types of building materials, including standard bricks, concrete blocks, wood, and precast concrete frames, evaluated with a full LCA and LCC non-flood low-flood, and high-flood conditions. The greenhouse gas analysis result showed that wood was the best option for constructing the building, while in case of flooding, the prefabricated concrete frame shows better performance by releasing less $\mathrm{CO}_{2}$ after the repair stage.

Life Cycle Cost has potential as an assessment tool for building energy-related strategies. For example, Fotiou, De Vita, and Capros (2019) designed an economic engineering model for the European Union (EU) building sector, which includes energy efficiency strategies and policies in the context of long-term deep decarbonization. In other energy-related research, simulation models applied to an apartment in a multi-family building in the United States show savings of $13.5 \%$ of the building's cost using a combination of passive and active energy strategies (Hajare and Elwakil 2020). Furthermore, LCC still implements slowly in the green building industry, especially for low-rise residential buildings. There is a need to extend this tool to the residential sector, where its growth hampers by inconsistent data and insufficient collaboration between the interested parties.

Allacker et al. (2019) combined the simulation with the LCA to evaluate the environmental impacts and benefits of the European Union buildings' innovation initiatives. Also, the software has been designed, such as EcoGen 2.1, which provides different design options to increase energy efficiency considering diverse bio-climatic and environmental requirements (Marsault and Torres 2019).

Dilsiz et al. (2019) analyzed, in a comparative study between residential and commercial buildings across 23 countries, the embodied energy during the operation stage using simulations in most cases. The results confirmed that energy use in a building concentrated in the operation stage with an average proportion of $72 \%$. The reduction of greenhouse gas emissions depends on the improvement of existing buildings, and that changes in the embodied energy are often obtained in new buildings or with profound modernization strategies.

The simulation of energy consumption supports decision-making. In Korea, Kim et al. (2018) evaluated the renovation of buildings considering environmental impacts and economic viability, carrying out energy simulations through the BIM methodology (Building Information Modeling), obtaining the energy-saving and financial variables to strengthen the decision-making process. The BIM methodology used in the LCC of sustainable building components. Pucko, Maucec, and Suman (2020) studied a school building in Slovenia, combined Archicad, Revit, and Tekla Structure to analyze the energy balance through dynamic simulation, and then they the economic evaluation of construction and operation costs. In this case, the simplified presentation of costs facilitated decision-making on the most cost-effective and energy-efficient building components.

However, LCA's application in buildings' structural design is rare, mainly because a structural design's principal objectives are safety and economic optimization. In general, the highest energy use of a building records in the operation stage, but as energy efficiency increases, the embodied energy takes more relevance in the environmental impact assessment. Today, a combination of strategies is needed to improve resource efficiency and reduce environmental impacts in buildings throughout the life cycle, including structural design. This situation has led to new guidelines on public procurement, such as Directiva 2014/24/UE, which requires architectural modeling tools and collaborative work promotion (EU 2020).

The LCA methodology becomes unfeasible for small building projects in the initial stages of design due to the quality and availability of information and the need for complex tools for quantification. Also, the concept of circular economics emphasizes the potential obstacles to developing metrics to quantify building sustainability. Among the proposals for architects and engineers to evaluate sustainability in the initial design phase are using more integrative approaches based on standardized indicators, identifying the most relevant parameters, and simplifying tools (Tabrizi and Brambilla 2019; Rahla et al. 2019).

Recently, this research line has strengthened with the incorporation of technological tools that facilitate information 
management. A recent case study of an office building in Los Angeles, Angeles et al. (2019) linked the building's potential geological risks to the LCA, using the software REVIT. The findings point out that variations in energy use in a building are mainly due to differences in the systems' limits that integrate it, the geographical location, the production processes, and the measurement methods. Despite the above, the risk analysis integrated with the LCA facilitates decision-making, and it is essential to follow the path of innovation and information management to reduce the environmental impacts of buildings significantly.

In another LCA case study conducted in Spain, Mercader et al. (2019) analyzed a set of dwellings built in reinforced concrete, including indicators of embodied energy, $\mathrm{CO}_{2}$ emissions, construction waste, demolition, urban solid waste, and construction costs. Software Revit, Presto, Medit, and the Andalusian Construction Cost Base (ACCD) integrated with the BIM methodology. The most relevant findings were: steel generates lower impacts than concrete when considering the potential for recycling and when comparing the foundation with the superstructure, the impacts are also lower in the former. In conclusion, it recognized the need to generalize this type of methodologies, limited by the information's disposition.

The LCC combines with simulations as well as the LCA. In Turkey, Güleroğlu et al. (2020) evaluated the potential for energy savings, the seismic behavior of the structure, and retrofitting costs, focusing on historical buildings with sociocultural value. Various renovation strategies analyzed through simulations and the application of the LCC, and it concluded that the implementation of new conditioning systems, as well as the inclusion of walls that fulfill the function of isolating and reinforcing the structure, are the most economic measures for improving the energy and seismic performance of this building.

Considering the cases analyzed above, the importance of environmental aspects, such as embodied energy, resource consumption, and carbon footprint, stands out in the building industry. Additionally, technological tools have facilitated the incorporation of the environmental aspect in decision-making at the project stage.

However, the fundamental processes of design and planning are still keeping. The technological tools currently used in the design and planning stage of buildings make information management more efficient, facilitate collaborative work, facilitate the detection of design improvements, and anticipate environmental risks and impacts, which reflect in greater project sustainability, but with high consumption of human and economic resources, making them inaccessible for small-scale projects. Despite the contribution of new technologies, they have a weak integration when projects are evaluated at the structural design stage, as is increasingly demanded by current public policies.

This research aims to present a method to select the optimal structural model by managing building information, including safety parameters, costs, and pollution emissions, generated by design and task planning software. For this purpose, the Environmental Economic Index (EEI) is presented, which integrates the parametric results of different structural options for the same building. This method's contributions are the integration and synthesis of structural, economic, and environmental variables in a single data or index, which contributes to the decision-making of designers and real estate developers. Given the complexity of carrying out an LCA, the proposal is a simple and economical alternative, which is not conditioned by the building's size, to include environmental variables in the structural design phase without including the operational phase. Finally, given that there is little research in this work line, this method can be used to design public policies oriented towards sustainability in the construction industry. In addition to the structural design, the tasks performed were calculating the costs of raw materials during the construction process, the amount of waste embodied energy, and the carbon footprint generated at the end of the construction process, thus obtaining a weighted index that supports decision-making.

\section{Methodology}

The working hypothesis for the development of the IEE is that the information on functionality, costs, and environmental impact, generated by the various technological tools used in the design stage can integrate into synthetic data that facilitates decision making when analyzing different structural proposals for a building.

In this research, the relationship between security and the economy analyzed through the limit state method. Most current structural design regulations, such as ACI codes, are based on that method and focus directly on the criteria for ultimate load, which states (eq. 1):

$$
\mathrm{FR}(\mathrm{AR})>\mathrm{FC}(\mathrm{AS})
$$


Inequality means that the structural elements (AR) capacity multiplied by a reduction factor, a conservative value. On the other side of the inequality, the internal forces (AS) generated by the loads that the structure should theoretically resist and multiplied by a factor that considers the probability that the actions' negative effect will increase. Regulations define each factor's value and, in a way, is a parameter about the level of security that society is willing to pay. The structural responses evaluate by a set of physical parameters, such as vibrations and cracks, rupture and collapse, to describe the behavior of the various actions, or loads, subject to during its lifetime. The actions, identified as loads, are mainly due to the building's weight, purpose, and local conditions such as wind and earthquakes.

Concerning the cost of a project, depending on the objectives and degree of precision that are necessary, there are different methodologies to carry out the estimation; if these objectives are focused on establishing the viability, comparing or analyzing the performance of different projects, the parametric method can be used (Cassanelli 2012). This method is executed in the early stages of the project when information is scarce and a high percentage of error is accepted; it is based on determining a series of critical characteristics, called parameters, correlated with the cost of the project and based on them, obtaining an estimate of the final cost (Sanchez et al. 2008). The results generate quickly and with reduced work, but with limited precision, its use in later stages of the project is not recommended because it incorporates a greater degree of uncertainty and risk.

It estimates the potential environmental impacts of construction materials focused on $\mathrm{CO}_{2}$ emissions, waste generation, and embedded energy. Natural resources were considered energy efficient, but modern ones are more durable and require less maintenance. It is modeled with reinforced concrete and structural steel, which are the most used construction materials today; of these, concrete is the most commercialized because it offers more advantages over other materials (Reynaga et al., 2013).

A three-story building was designed architecturally and structurally for the infrastructure of an educational institution located in a municipality in north-central Mexico to define the project's social objective. The architectural design based on the Revit (v2018) software from AUTODESK, and later it was exchanged, in IFC format, to the structural calculation CYPECAD (v2017.e) software, developed by the company CYPE Ingenieros SA.

The structural optimization was carried out with the CYPECAD software. Various proposals for the building structure modeled with it; the differences presented in the combinations of actions to which it subjected and the geometries and structural materials used. In the initial stage, the design loads were gravity loads with the wind, and later the seismic action was included. These actions were applied to reinforced concrete or structural steel structural systems, resulting in six designs for the projected building; the parametric evaluation of the various structural models generated from the design program's worklists. The price bank considers each work's specific characteristics to generate specific amounts for the project budgeted, resulting in material execution costs, direct costs (material, labor, tools), adjusted to the market; its catalog includes manufacturers and generic products. The version used was 2017, and the prices correspond to April of that year.

This work's environmental impacts were also obtained with the "Generador de Precios" software, as it allows accounting for each structural element, waste generated, embodied energy, and $\mathrm{CO} 2$ emissions. According to the developers, the program helps analyze the different phases of the building life cycle, from preliminary studies, preliminary design, basic and execution design, construction management and execution, use and maintenance, demolition, and final recycling. The software is validated by the Spanish government agency that evaluates and certifies buildings' sustainability (CYPE 2019).

In this phase of the process, it is important to highlight two points: in this study, the environmental assessment was carried out on the global warming category, using the Carbon Footprint technique, the generation of waste and the embodied energy during the construction phase of the structure; secondly, there are no databases for Mexico. Therefore the results of the environmental impact are based on data from Spain. Consequently, the estimates can only indicate the magnitude of $\mathrm{CO} 2$ emissions, embodied energy, and waste generated by the construction activities of the building structure analyzed.

Finally, with the information from the project's design and management stages, it was normalized to integrate the EEI and evaluate the various structural models. The index only incorporates the costs of the structure's execution and the embodied energy in the construction stage of the structure; therefore, these calculations are only performed once during the entire useful life of the building. The following parameters were used in the research to construct the index: structural security (social dimension), building costs (economic dimension), waste, energy, and emissions (environmental dimension). The method in Figure 1 integrates these different variables. 


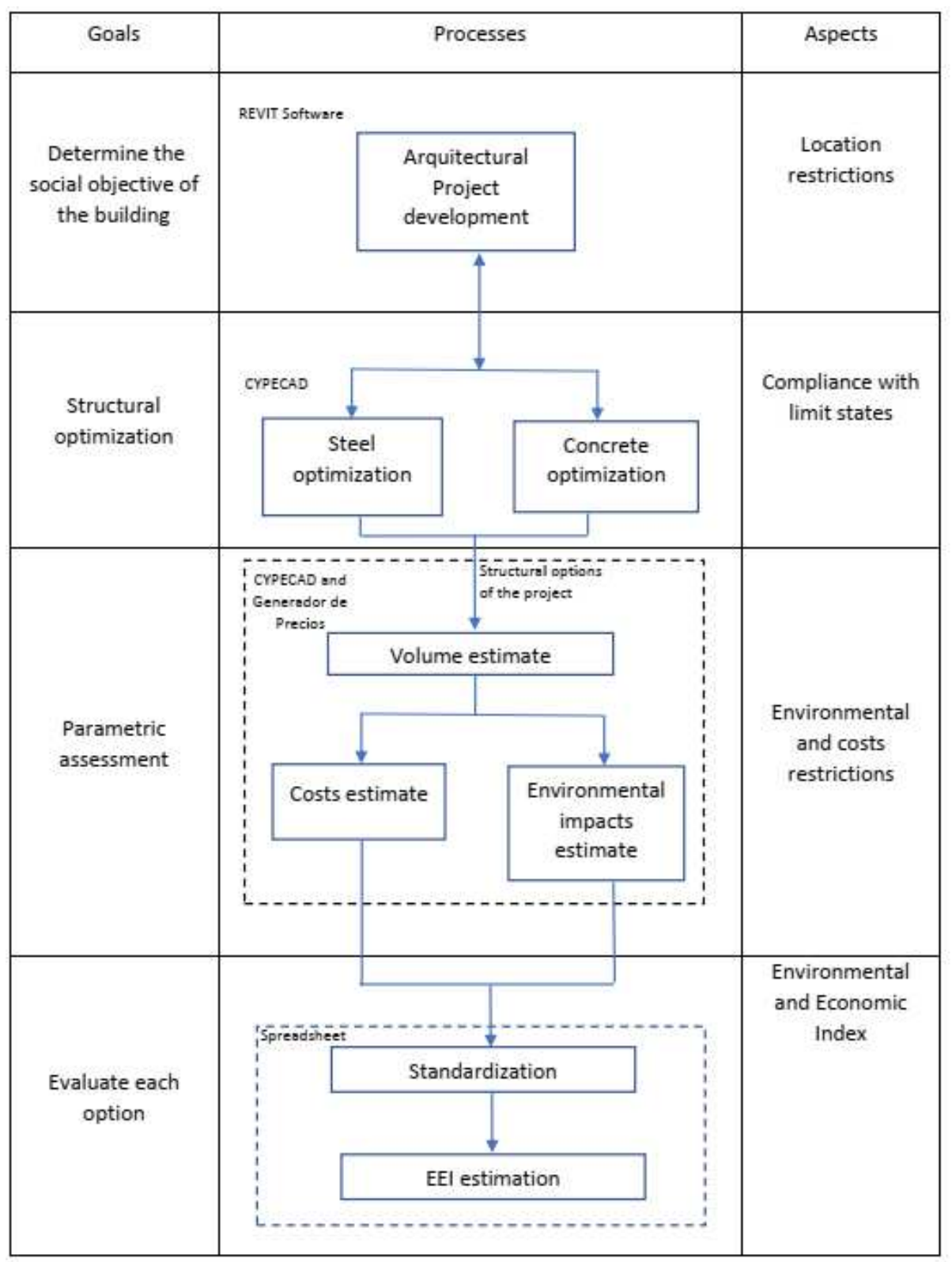

Figure 1. EEI Method.

Source: The authors.

This method bases on Sepulveda's (2008) proposal, which normalizes different origin indicators and integrates them into an index. In this case study, the index was called the Environmental Economic Index (EEI), and it allows us to compare, through unique data, different structural models proposed for the same building.

In its original form, the parameters that make up the index have multiple units of measurement, which corrects by normalization. This procedure consists of transforming the value of each parameter to a scale ranging from " 0 " to " 1 " by applying the following relativization function (eq. 2):

$$
f(x)=\frac{x-M}{m-M}
$$

where " $\mathrm{x}$ " is the specific parameter value of a structure, " $\mathrm{m}$ " is the minimum parameter value in the set of structures analyzed, and "M" is the maximum level. The structure with a value "1" will show the best performance in the parameter, and at the 
opposite end will be located the worst performance. Finally, the index was obtained by calculating the weighted average of the relativized parameters as indicated in eq. (3):

$$
E E I=\Sigma F_{P} f(x)
$$

It is essential to mention that the term performance is conceptualized differently from performance design, usually in structural engineering. Design for structural performance includes acceptance criteria for the analysis and design of structures, focusing on the most probable behavior, controlling structural and non-structural damage, and the safety levels required when the soil transmits the seismic action.

The index results can be differentiated using a color scale and summarized in a graph, which facilitates comparative analysis since the imbalances between models and parameters are displayed both qualitatively and quantitatively. The color scale proposed to describe the performance of each building is the following:

- $\operatorname{Red}^{(*)}$ :

- Orange ${ }^{(* *)}$ :

- Yellow ${ }^{(* * *)}$ :

- $\mathrm{Green}^{(* * *)}$ :

EEI $<0.2$, Very low.

$0.2 \leq \mathrm{EEI}<0.4$, Low.

$0.4 \leq \mathrm{EEI}<0.6$, Regular.

- Blue $\mathrm{e}^{(* * * * *)}$ :

$0.6 \leq \mathrm{EEI}<0.8$, Acceptable.

$0.8 \leq \mathrm{EEI} \leq 1.0$ Very acceptable.

A radar chart can also represent the values obtained for the EEI for each structural proposal. In this graph, each axis represents an analysis variable, and the values range from 0 to $1 ; 0$ is equivalent to low performance and 1 to the maximum. The larger and more homogeneous the area, the better the project under analysis will provide (Sepúlveda, 2008). By being able to represent the results obtained graphically, it is possible to observe in a single image the imbalances of the whole, which facilitates the identification of the aspects of the structural project that can be improved, as well as the priority variables to carry out an efficient process with less negative impacts.

\section{Case Study}

As a case study, a three-story building with a roof with a total area of $6088 \mathrm{~m} 2$ proposed accommodating 220 parking spaces for automobiles; other uses contemplated to include commercial spaces on the first floor and a gymnasium on the third level. The architectural project proposed that the building would be integrated into a higher education center's existing infrastructure, and the users would be students and academics. The site chosen is the Campus Zona Media of the UASLP, in Rioverde, San Luis Potosí; this determines the functional and safety characteristics and the market conditions, costs, and emissions.

Pedestrian access to the different building levels is provided by two staircases, while vehicles access the building through ramps in the central part of the building; these ramps have the dual function of providing access and accommodating parking spaces. The commercial spaces, located on the first floor, are independent of the parking lot and have access through the building's main facade.

The proposed structural system was rigid frames, with bidirectional floor systems (waffle slab) in reinforced concrete columns and beams, and unidirectional systems (steel deck) when the structure was designed with structural steel. Other elements, such as walls, were not considered structural but as permanent loads - the foundations were designed depending on the design loads, using isolated footing and foundation beams.

In the regulatory and safety aspect, the official website of the National Center for Disaster Prevention of the Government of Mexico (CENAPRED, 2019) recognizes that this country is the only one in Latin America that does not have a building regulation at the national level. Article 115 of the United Mexican States' Political Constitution interprets that each municipality has the attribution to issue its own, a task that is pending in various localities of the country. On the website of the Sociedad Mexicana de Ingeniería Estructural, A.C. (SMIE, 2021), it can be seen that, in the case of the state of San Luis Potosí, there are only regulations for the municipality of the same name, which is the state capital, and that the remaining 57 municipalities do not have regulations defining the necessary structural criteria. 
In terms of the technology and disposition of constructive materials, first, it was modeled with reinforced concrete and later with structural steel. Other options, such as precast concrete elements, which could work optimally in this type of building, were discarded because they are not available locally, significantly modifying the cost and impact analysis results.

As design actions, the weights of the different materials, the user load, and the wind initially considered; in the second stage, the earthquake was added as an accidental action, resulting in three structural models with gravitational loads plus wind three with the gravitational loads plus earthquake. The analyzed structures were:

- Es_1: Reinforced concrete model analyzed without seismic action.

- Es_2: Structural steel model, with columns formed by tubular, analyzed without including seismic action.

- Es_3: Structural steel model, with columns formed by composite pieces, analyzed without including seismic action.

- Es_1S: Reinforced concrete model analyzed with seismic action.

- Es_2S: Structural steel model, with columns formed by tubular, analyzed with seismic action.

- Es_3S: Structural steel model, with columns formed by composite pieces, analyzed with seismic action.

The design codes used were Building Code Requirements for Structural Concrete (ACI 318_11) and Commentary and ASCE Standard ASCE/SEI 7-10: Minimum Design Loads for Buildings Other Structures, as well as the Federal Electrical Commission's Wind and Earthquake Design Manuals. Although all models comply with the limit states, the latter's safety is more significant due to their seismic design.

The architectural project was carried out with the REVIT 2018 software (Fig. 2) and was later transferred, in IFC format, to the CYPECAD software developed by the company CYPE Ingenieros SA to obtain the structural calculation of each building (Fig. 3, 4).

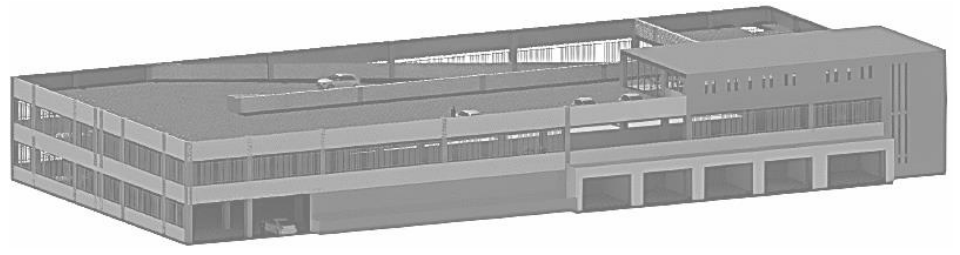

Figure 2. Architectural model.

Source: The authors.

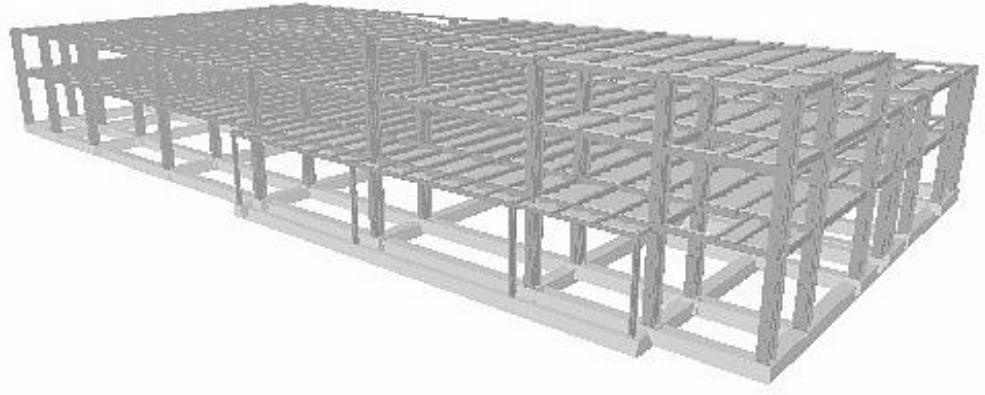

Figure 3: Steel model, with composite columns

Source: The authors. 


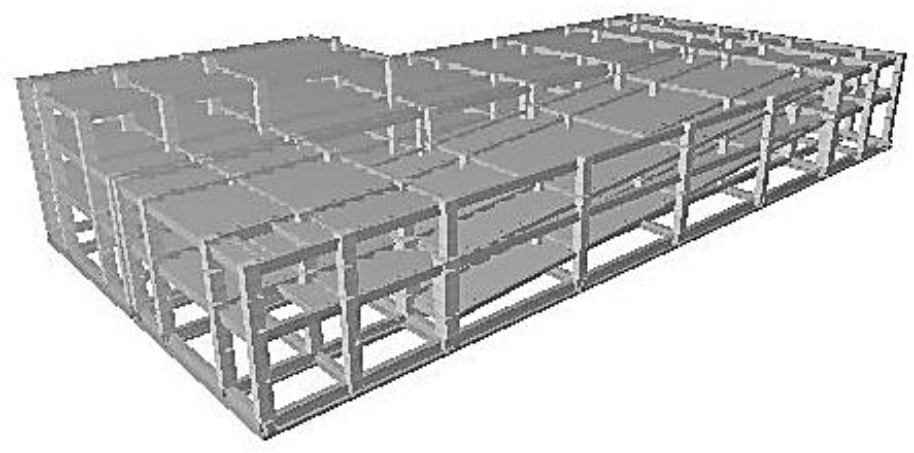

Figure 4 Structural model in reinforced concrete.

Source: Own elaboration

Depending on the actions and characteristics of the soil, the foundation is either of the surface types with isolated footings and bonding elements or of continuous footings with counter beams; in all cases, the superstructure resolved with rigid frames of beams and columns that comply with the limit states of failure and service.

Prismatic elements of different dimensions integrate the reinforced concrete structures. The floor system is a waffle slab with a total cant of $40 \mathrm{~cm}(33+7)$; the casing is of expanded polystyrene $(64 \times 64 \times 33 \mathrm{~cm})$, and the ribs are $16 \mathrm{~cm}$, cast "in situ." The concrete is exposed to a humid environment; its resistance is $250 \mathrm{~kg} / \mathrm{cm}^{2}$ and poured with pumping equipment. As for the reinforcement steel, it will be prepared on-site. The formwork systems, made of wood or metal, are recoverable and amortizable in several uses, depending on whether they are used in foundations or the superstructure.

In the steel structure, there are two solutions: in both cases, the beams are simple "I" sections, but the columns are double "I" sections in a box with a generic joint or simple circular tubular. As a floor system, a collaborating galvanized steel and a concrete sheet were chosen. For reasons of economy, the use of profiles reduces to those facilitating the making of connections. The cant beams that make up the rigid frames established according to the critical sections since all the elements that contribute to a column standardized to facilitate the transmission of forces and the material execution of the connection; another selection criterion was that the cant of the main beams should at least equal that of the secondary beams. This standardization of beams and columns results in similar sections per floor and block.

\section{Results and discussion}

Parametric assessment starts with the work lists generated by the design software. The material execution costs or direct costs (material, labor, tooling) are estimated using the "Generador de Precios" module of the CYPE software. This module allows the environmental evaluation of buildings up to the construction phase. Its information is an input for the index; the calculations are based on $\mathrm{CO}_{2}$ emissions obtained from the volumes by an impact factor. It is essential to highlight that the estimates presented can only be seen as indicative for two aspects: in the research, the environmental evaluation was only carried out using the carbon footprint technique, the estimation of waste and embodied energy; the second, that there are no databases for Mexico, so the results of the environmental impact are based on data from Spain.

Table 1 shows the unit results of costs and environmental impacts for concrete buildings subjected to gravitational loads and wind (ES_1) in the construction stage. Similarly, all the buildings' parameters were obtained using the "Generador de Precios." 
Table 1. Costs e impacts in the concrete building without seismic strength (Es_1).

\begin{tabular}{|c|c|c|c|c|c|c|c|c|c|}
\hline \multirow{3}{*}{ Element } & \multirow{3}{*}{$\begin{array}{c}\text { Cost } \\
(\$ \\
\text { Thousands })\end{array}$} & \multicolumn{2}{|c|}{ Waste generated } & \multicolumn{3}{|c|}{ Energy consumption (MJ) } & \multicolumn{3}{|c|}{ Emissions $\mathrm{CO}_{2}$ eq. (kg) } \\
\hline & & \multirow{2}{*}{ Weight (kg) } & \multirow{2}{*}{ Volume (1) } & \multirow{2}{*}{$\frac{\text { Manufacturing }}{\mathrm{A} 1-\mathrm{A} 2-\mathrm{A} 3}$} & \multicolumn{2}{|c|}{ Construction } & \multirow{2}{*}{$\frac{\text { Manufacturing }}{\mathrm{A} 1-\mathrm{A} 2-\mathrm{A} 3}$} & \multicolumn{2}{|c|}{ Construction } \\
\hline & & & & & A4 & A5 & & A4 & A5 \\
\hline Pad foundation & 612.4 & 3,068 & 1,943 & $1,343,104$ & 18,602 & 14,760 & 118,009 & 1,376 & 1,100 \\
\hline Strap beams & 518.0 & 2,151 & 1,365 & $1,166,815$ & 13,834 & 5,633 & 98,052 & 1,024 & 425 \\
\hline Tie beams & 131.8 & 649 & 391 & 307,937 & 3,597 & 1,402 & 25,779 & 266 & 106 \\
\hline Subtotal & 1262.2 & 5,868 & 3,699 & $2,817,857$ & 36,034 & 21,794 & 241,840 & 2,666 & 1,630 \\
\hline Beams & 2065.5 & 11,266 & 7,395 & $3,599,401$ & 48,345 & 99,856 & 312,983 & 3,577 & 7,433 \\
\hline Columns & 801.5 & 4,258 & 2,348 & $1,785,489$ & 20,854 & 30,474 & 149,974 & 1,543 & 2,270 \\
\hline Slabs & 3339.5 & 17,376 & 11,787 & $5,986,715$ & 135,833 & 99,096 & 486,262 & 10,049 & 7,399 \\
\hline Subtotal & 6206.5 & 32,899 & 21,530 & $11,371,605$ & 205,032 & 229,426 & 949,219 & 15,170 & 17,102 \\
\hline Total & 7468.7 & 38,768 & 25,229 & $14,189,462$ & 241,066 & 251,221 & $1,191,059$ & 17,836 & 18,732 \\
\hline Cost/ $\mathrm{m}^{2}$ (structure) & \multicolumn{9}{|c|}{$\$ 1,020$} \\
\hline Waste and emissions $/ \mathrm{m}^{2}$ & & 5.4 & 3.5 & $1,868.0$ & 33.7 & 37.7 & 155.9 & 2.5 & 2.8 \\
\hline Total, Cost/ $\mathrm{m}^{2}$ & \multicolumn{9}{|c|}{$\$ 1,227$} \\
\hline Waste, energy, and emissions $/ \mathrm{m}^{2}$ & & 6.4 & 4.1 & $2,330.9$ & 39.6 & 41.3 & 195.7 & 2.9 & 3.1 \\
\hline $\begin{array}{l}\text { A1. Raw material supply } \\
\text { A4. Transport to the building site } \\
\text { Source: The authors. }\end{array}$ & \multicolumn{6}{|c|}{$\begin{array}{l}\text { A2. Transport to the manufacturer } \\
\text { A5. Construction and installation }\end{array}$} & & & \\
\hline
\end{tabular}

The estimated direct cost (7.5 million pesos) includes materials, labor, and tools; no installations, facades, partitioning, or finishing include. For these buildings, the structure's cost is approximately 50-60\% of the total, so conservatively, we could estimate the total direct cost of the parking lot at 15 million pesos by 2017. By charging a $28 \%$ cost overrun factor to include indirect costs and profit, the final cost of construction in that year was 19.2 million pesos, or $\$ 3,160 / \mathrm{m} 2$ (CMIC a,b,c 2018). In terms of impacts, the initial phases corresponding to the manufacture of construction materials produce the most significant impacts, and the material that generates the most emissions is reinforcing steel.

Cost analysis of all structures shows that concrete structures are the most economical. If the seismic load is considered, the structural safety is improved, and using the standard building techniques in the study area, represents cost overruns that may not be significant (22\%) compared to potential losses (Fig. 5).

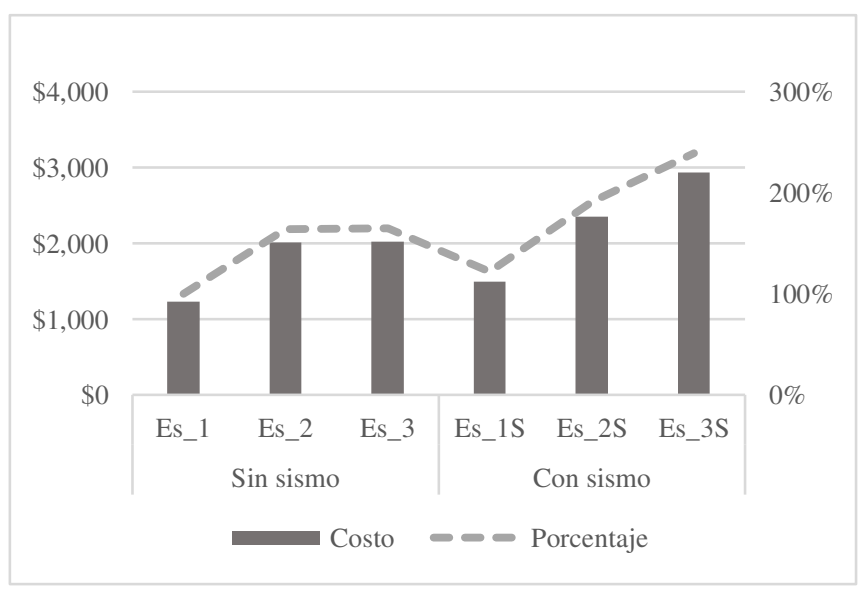

Figure 5: Direct building costs (m2)

Source: The authors.

Considering that there are essential locational differences, these estimates are similar to those recently presented in their technical and economic analysis of various structural models for buildings designed under the Ecuadorian Construction Standard NEC-15 (Guerrero 2019). 
Similarly, the results of the environmental impacts indicate that most of the embodied energy and the $\mathrm{CO}_{2}$ emissions come from the production and transport of materials to the site (over $90 \%$ in all cases); only a tiny fraction is used in the construction process. Likewise, the highest proportion corresponds to the dominant materials, which in this analysis are concrete and steel, the latter being the one that generates the most significant impacts. In terms of waste, concrete buildings generate up to $100 \%$ more than structural steel buildings, but volumes, in general, are not the most relevant impacts (Table 2).

Table 2. Comparison of model parameters.

\begin{tabular}{|c|c|c|c|c|c|}
\hline \multirow{3}{*}{ Parameters } & \multicolumn{2}{|c|}{ Waste generated } & \multicolumn{3}{|c|}{ Emissions $\mathrm{CO}_{2}$ eq. (kg) } \\
\hline & \multirow{2}{*}{ Weight $(\mathrm{kg})$} & \multirow{2}{*}{ Volume (1) } & \multirow{2}{*}{$\frac{\text { Manufacturing }}{\mathrm{A} 1-\mathrm{A} 2-\mathrm{A} 3}$} & \multicolumn{2}{|c|}{ Construction } \\
\hline & & & & $\mathrm{A} 4$ & $\mathrm{~A} 5$ \\
\hline \multicolumn{6}{|c|}{ Concrete without seismic strength (Es_1) } \\
\hline Structure $/ \mathrm{m}^{2}$ & 5.4 & 3.5 & 156 & 2 & 3 \\
\hline Total $/ \mathrm{m}^{2}$ & 6.4 & 4.1 & 196 & 3 & 3 \\
\hline Structure $/ \mathrm{m}^{2}$ & \multicolumn{5}{|c|}{$\$ 1,019.54$} \\
\hline Total/ $\mathrm{m}^{2}$ & & & $\$ 1,226.87$ & & \\
\hline \multicolumn{6}{|c|}{ Metal tubular columns without seismic strength (Es_2) } \\
\hline Structure $/ \mathrm{m}^{2}$ & 3.6 & 2.1 & 273 & 2 & 1 \\
\hline Total $/ \mathrm{m}^{2}$ & 4.4 & 2.6 & 303 & 3 & 1 \\
\hline Structure $/ \mathrm{m}^{2}$ & \multicolumn{5}{|c|}{$\$ 1,839.80$} \\
\hline Total/ $\mathrm{m}^{2}$ & & & $\$ 2,008.11$ & & \\
\hline \multicolumn{6}{|c|}{ without seismic strength (Es_3) } \\
\hline Structure $/ \mathrm{m}^{2}$ & 3.8 & 2.2 & 286 & 3 & 1 \\
\hline Total $/ \mathrm{m}^{2}$ & 4.7 & 2.7 & 315 & 3 & 1 \\
\hline Structure $/ \mathrm{m}^{2}$ & \multicolumn{5}{|c|}{$\$ 1,858.12$} \\
\hline Total/ $\mathrm{m}^{2}$ & & & $\$ 2,020.01$ & & \\
\hline \multicolumn{6}{|c|}{ Concrete under seismic strength (Es_1S) } \\
\hline Structure $/ \mathrm{m}^{2}$ & 6.6 & 4.2 & 3 & 3 & 3 \\
\hline Total $/ \mathrm{m}^{2}$ & 8.7 & 5.6 & 276 & 4 & 4 \\
\hline Structure $/ \mathrm{m}^{2}$ & \multirow{2}{*}{\multicolumn{5}{|c|}{$\begin{array}{l}\$ 1,265.15 \\
\$ 1,493.89\end{array}$}} \\
\hline Total/ $\mathrm{m}^{2}$ & & & & & \\
\hline \multicolumn{6}{|c|}{ Metal tubular columns under seismic strength (Es_2S) } \\
\hline Structure $/ \mathrm{m}^{2}$ & 4.1 & 2.3 & 312 & 3 & 1 \\
\hline Total $/ \mathrm{m}^{2}$ & 5.8 & 3.5 & 357 & 7 & 1 \\
\hline Structure $/ \mathrm{m}^{2}$ & \multicolumn{5}{|c|}{$\$ 2,047.14$} \\
\hline Total/ $\mathrm{m}^{2}$ & & & & & \\
\hline \multicolumn{6}{|c|}{$\frac{\$ 2,348.92}{\text { Metal columns inbox under seismic strength (Es_3) }}$} \\
\hline Structure $/ \mathrm{m}^{2}$ & 5.3 & 3.0 & 423 & 4 & 1 \\
\hline Total $/ \mathrm{m}^{2}$ & 7.1 & 4.2 & 468 & 7 & 1 \\
\hline Structure $/ \mathrm{m}^{2}$ & & & $\$ 2,619.46$ & & \\
\hline $\mathrm{Total} / \mathrm{m}^{2}$ & & & $\$ 2,933.02$ & & \\
\hline
\end{tabular}

Source: The authors.

The above parameters, which individually are indicators of each building's potential performance, when integrated as an index, facilitate the selection of the structural model that will offer adequate functionality with less impact during its construction.

The EEI built developing the same analysis for each of the buildings. The weighting of each parameter made from the concept of sustainability and its three dimensions: safety $34 \%$, costs $33 \%$, and the remaining percentage distributed among the various environmental impacts, giving more weight to the component of the manufacture of materials (A-1, A-2, and A-3) for its importance concerning the total dimension. These results also include the stages of transportation of the product (A-4) to the construction site and construction (A-5), but these are perhaps the most questionable since the geographical contexts and the construction procedures differ and, consequently, modify the estimates. This undesirable effect mitigates when all structures analyze in the same context.

The rating of each of the structures is as follows (Table 3). In the table, the parameters "Energy 1" and "Emission 1" correspond to the manufacturing stage of the material, while "Energy 2" and "Emission 2" reflect the transport and construction stages: 


\begin{tabular}{|c|c|c|c|c|c|c|}
\hline \multirow[t]{2}{*}{ Weighting (\%) Normalization } & \multicolumn{3}{|c|}{ Without seismic forces } & \multicolumn{3}{|c|}{ Under seismic forces } \\
\hline & Es_1 & Es_2 & Es_3 & Es_1S & Es_2S & Es_3S \\
\hline Safety (34.0) & 0.6 & 0.6 & 0.6 & 1.0 & 1.0 & 1.0 \\
\hline$f(x)$ & 0.00 & 0.00 & 0.00 & 1.00 & 1.00 & 1.00 \\
\hline Costs (33.0) & 1227 & 2008 & 2020 & 1494 & 2349 & 2933 \\
\hline$f(x)$ & 1.00 & 0.54 & 0.54 & 0.84 & 0.34 & 0.00 \\
\hline Energy $1(12.5)$ & 2331 & 4004 & 4160 & 3275 & 4685 & 6205 \\
\hline$f(x)$ & 1.00 & 0.57 & 0.53 & 0.76 & 0.39 & 0.00 \\
\hline Energy $2(3.0)$ & 81 & 48 & 51 & 102 & 96 & 108 \\
\hline$f(x)$ & 0.46 & 1.00 & 0.94 & 0.11 & 0.20 & 0.00 \\
\hline Emission 1 (12.5) & 196 & 303 & 315 & 276 & 357 & 468 \\
\hline$f(x)$ & 1.00 & 0.61 & 0.56 & 0.71 & 0.41 & 0.00 \\
\hline Emission 2 (3.0) & 6 & 4 & 4 & 8 & 8 & 9 \\
\hline$f(x)$ & 0.53 & 1.00 & 0.95 & 0.22 & 0.18 & 0.00 \\
\hline Waste (2.0) & 6 & 4 & 5 & 9 & 6 & 7 \\
\hline$f(x)$ & 0.55 & 1.00 & 0.95 & 0.00 & 0.68 & 0.38 \\
\hline \multirow[t]{2}{*}{ Environmental Economic Index } & 0.62 & 0.41 & 0.39 & 0.81 & 0.58 & 0.35 \\
\hline & $* * * *$ & $* * *$ & $* *$ & $* * * * *$ & $* * *$ & $* *$ \\
\hline
\end{tabular}

Source: The authors.

Each building's index's values showed that the structure that presents a very acceptable result is the reinforced concrete one submitted to seismic load. At an economical cost, its security is high; besides, obtaining its materials implies less consumption of energy and emissions; its disadvantages are that the constructive processes are more elaborated, the reason why its emissions and remainders are greater than structural steel. On the opposite side is the steel structure with composite profiles: higher costs and high generation of both waste and emissions in all construction stages. The comparison of EEI for each structural model shows in the radar chart of Figure 6.

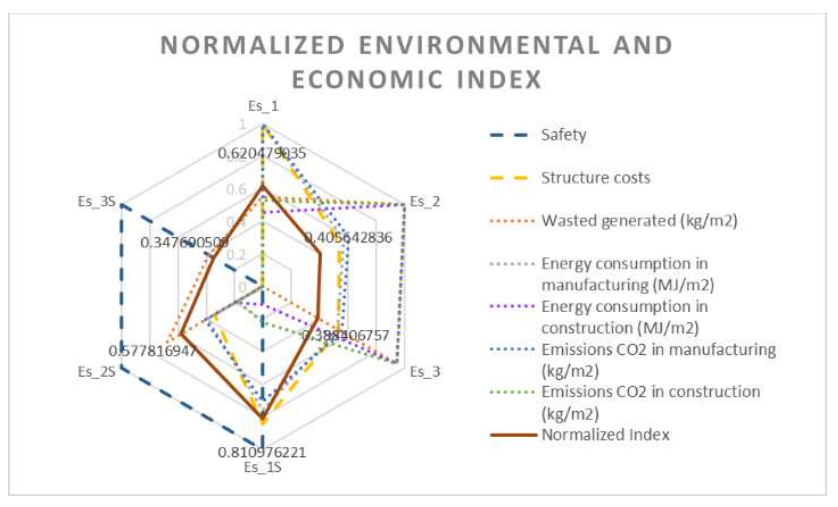

Figure 6: EEI, including phase A-4.

Source: The authors.

When the A-4 phase is removed from the index, the structures with the best and worst results (seismic strength concrete and steel with composite sections, respectively) are the same. However, due to its safety and apparent constructive simplicity, the steel structure with simple pieces that previously showed a regular result now records an acceptable result despite its cost and emissions (Fig. 7). 


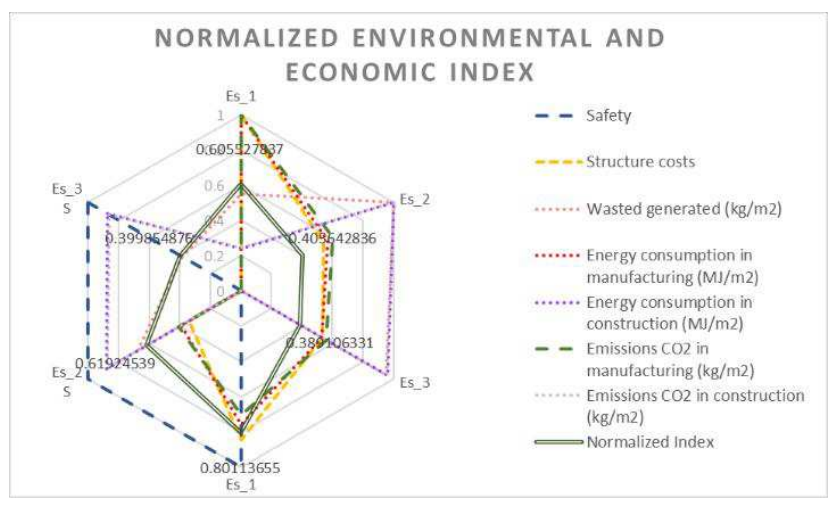

Figure 7: Environmental and Economic Index (without phase A-4). Source: The authors.

In general, based on the results of the EEI, it could be determined that for buildings similar to the one analyzed and in the proposed regional context, the optimal structural option is the use of reinforced concrete frames. However, their massiveness implies a greater intensity of design actions, the economy in their costs, and the lower overall amount of environmental impacts make them a suitable option.

\section{Conclusions}

Sustainability implies a balance between multiple variables and the evaluation of different options. Therefore, the management of building projects must consider, in addition to functional and economic conditions, the availability and quality of environmental resources. In this line, the EEI methodology standardizes a set of structural and management parameters by presenting a single, easy-to-read piece of information.

After generating the IEE for each structural model for this case study, the best performance structure is the one with rigid reinforced concrete frames and bidirectional floor systems. Although higher safety criteria include higher costs, between 17 and $22 \%$, it should not be forgotten that the structural design philosophy is optimization. In terms of carbon footprint, the manufacturing stage's best structural option continues to be reinforced concrete, 30 to $40 \%$ lower than the structural steel option. However, this ratio changed at the construction stage, where the difference between the concrete option was $40 \%$ higher than the structural steel option. In a waste generation, the best options have always been the structural steel option. In this sense, it is essential to develop and incorporate materials with better mechanical performance and more technical construction processes.

Likewise, the methodological proposal highlights the processes and materials that produce the highest costs and impacts during the construction process and helps improve the building's management in its initial phase. The results suggest that each improvement should focus on energy savings in construction, manufacturing, and transportation of materials, prioritizing those with low embodied energy. The reduction of the total amount of embodied energy requires, in addition to economic and structural optimization, the use of local materials and mineral, organic, and construction waste. In industrialized materials, optimization is associated with the reduction of the weight of the material used per square meter of constructed surface; for example, by minimizing the sections or thicknesses of the components, complying with the established limit states.

The proposed methodology helps make investment decisions and could contribute to better public policies focused on building. The mandatory incorporation of safety criteria more relevant to the local context and the evaluation of impacts through simplified technologies such as EEI in the management of any building project could be a technical measure that contributes to mitigating the negative impacts of this productive activity.

In terms of safety, and depending on both the results obtained and the potential effects that accidental actions have, assuming higher standards through the mandatory review of all buildings' seismic behavior is a measure that seems necessary. This increase in performance demands, in any case, should also be reflected in new and better structural systems, as well as in more efficient construction processes; in this way, the attributes of the building are perfected with cost overruns that are not excessive, thus fulfilling the purpose of the structural design. Punctually, for the analyzed buildings, the probable seismic actions can be controlled using concrete structures since they are the ones with the lowest cost and embodied energy, but it would be advisable to improve the constructive processes so that their handmade component is reduced.

A limitation to the proposed methodology is that inherent to any parametric evaluation since they have the weak point of considering that the industrialization processes and the life cycles of the products are homogeneous in their levels of uncertainty 
and risks and the work teams during the different stages involved. Therefore, it recommends that the results of each product's carbon footprint be analyzed with reserve or obtained in another way because the databases of emissions are not local and are only a reference value; the same happens with the waste generated and the embodied energy. For each project, due to its location and material disposition, it is advisable to analyze each of the variables' weighting. It is considered pertinent to adjust this weighting through a sensitivity analysis that includes a more significant number of cases.

Finally, the EEI could contribute to the project's cost management and estimate in origin some of the environmental impacts associated with the building processes, and it does not solve all the problems that have to do with the critical analysis of the life cycle and the costing of this one. It is essential to reflect that it does not solve any problem in itself or that its estimation may be inappropriate without technical knowledge based on architectural, technical standards, structural safety, and building and environmental management. This method has particular information management, which is not a complete LCA or LCC study, so it is not advisable to compare it with others because they exchange information but do not integrate it synthetically. The possibility of continuing to work on this research line, extending beyond the initial phase of the structural project, remains open.

\section{References}

GlobalABC/IEA/UNEP a (Global Alliance for Buildings and Construction, International Energy Agency, and the United Nations Environment Programme) (2020) GlobalABC Roadmap for Buildings and Construction: Towards a zero-emission, efficient and resilient buildings and construction sector, IEA, Paris.

IEA (International Energy Agency) (2019) World Energy Outlook 2019. Paris: IEA. https://doi.org/10.1787/caf32f3b-en

Goubran S and Cucuzzella C (2019) Integrating the Sustainable Development Goals in Building Projects. J Sustain Res. https://doi.org/10.20900/jsr20190010

United Nations (2020) The Sustainable Development Goals Report 2020. United Nations. https://unstats.un.org/sdgs/report/2020/The-Sustainable-Development-Goals-Report-2020.pdf

GlobalABC/IEA/UNEP b (Global Alliance for Buildings and Construction, International Energy Agency, and the United Nations Environment Programme) (2020): GlobalABC Regional Roadmap for Buildings and Construction in Latin America: Towards a zero-emission, efficient and resilient buildings, and construction sector. IEA, Paris.

World Green Building Council (2019) Bringing Embodied Carbon Upfront - Coordinated Action for the Building and Construction Sector to Tackle Embodied Carbon. Accessed 14 August 2020 https://worldgbc.org/news-media/bringingembodied-carbon-upfront

Saade MR, Guest G and Amor B (2020) Comparative whole building LCAs: How far are our expectations from the documented evidence? Building and environment. https://doi.org/10.1016/j.buildenv.2019.106449

International Organization for Standardization (2020) ISO 14044:2006 Environmental management-life cycle assessmentrequirements and guidelines (en). http://www.iso.org/iso/home.html. Accessed 14 August 2020.

International Organization for Standardization (2020) ISO 15686-5:2017 (en) Buildings and constructed assets- Service-life planning-Part 5: Life-cycle costing. https://www.iso.org/obp/ui/\#iso:std:iso:15686:-5:ed-2:v1:en Accessed 16 August 2020

Balasbaneh AT, Bin M and Gohari A (2019) Sustainable materials selection based on flood damage assessment for a building using LCA and LCC. J of Cleaner Production. https://doi.org/10.1016/j.jclepro.2019.03.005

Fotiou T, De Vita A and Capros P (2019) Economic-Engineering Modelling of the Buildings Sector to Study the Transition towards Deep Decarbonisation in the EU. https://doi.org/10.3390/en12142745

Hajare A and Elwakil E (2020) Integration of life cycle cost analysis and energy simulation for building energy-efficient strategies assessment. Sustainability Cities and Society. https://doi.org/10.1016/j.scs.2020.102293

Allacker K, Castellani V and Baldinelli G et al. (2019) Energy simulation and LCA for macro-scale analysis of ecoinnovations in the housing stock. Int J Life Cycle Assess. https://doi.org/10.1007/s11367-018-1548-3

Marsault X and Torres F (2019) An interactive and generative eco-design tool for architects in the sketch phase. J Physics: Conference Series. https://iopscience.iop.org/article/10.1088/1742-6596/1343/1/012136 
Dilsiz A D, Felkner J, Habert G and Nagy Z (2019) Embodied versus operational energy in residential and commercial buildings: where should we focus? J Physics: Conference Series. http://dx.doi.org/10.1088/1742-6596/1343/1/012178

Kim J-U, Hadadi OA, Kim H and Kim J (2018) Development of A BIM-Based Maintenance Decision-Making Framework for the Optimization between Energy Efficiency and Investment Costs. Sustainability. https://doi.org/10.3390/su10072480

Pučko Z, Maučec D and Šuman N (2020) Energy and Cost Analysis of Building Envelope Components Using BIM: A Systematic Approach. Energies. https://www.mdpi.com/1996-1073/13/10/2643

EU (2020) Directiva 2014/24/UE del Parlamento Europeo y del Consejo de 26 de febrero de 2014 sobre contratación pública y por la que se deroga la Directiva 2004/18/CE. https://eur-lex.europa.eu/legalcontent/ES/TXT/PDF/?uri=CELEX:32014L0024\&from=ES. Accessed September 4, 2020

Tabrizi TB and Brambilla A (2019) Toward LCA-lite: A Simplified Tool to Easily Apply LCA Logic at the Early Design Stage of Building in Australia. European Journal of Sustainable Development, 8(5), 383. https://doi.org/10.14207/ejsd.2019.v8n5p383

Rahla KM, Bragança L and Mateus R (2019) Obstacles and barriers for measuring building's circularity. IOP Conf Ser: Earth Environm Sci. https://iopscience.iop.org/article/10.1088/1755-1315/225/1/012058/pdf

Angeles K, Patsialis D, Kijewski-Correa T, Taflanidis A, Vardeman II CF and Buccellato A (2019) Advancing Resilient and Sustainable Buildings through a New Normative Workflow for Integrated Life-Cycle Assessments. Int Conf on Sustainable Infrastructure 2019: Leading Resilient Communities through the 21st Century. https://doi.org/10.1061/9780784482650.070

Mercader MP, Camporeale PE and Cózar-Cózar E (2019) Evaluación de impacto ambiental mediante la introducción de indicadores a un modelo BIM de vivienda social. Hábitat sustentable. https://doi.org/10.22320/07190700.2019.09.02.07

Güleroğlu SK, Karagüler ME, Kahraman I and Umdu ES (2020) Methodological approach for performance assessment of historic buildings based on seismic, energy and cost performance: A Mediterranean case. J Building Engineering. https://www.sciencedirect.com/science/article/pii/S2352710219325914

Cassanelli A (2012) Proyectos de I+D, aplicación de metodologías de gestión de proyectos. Ib J Project Management. https://doi.org/10.13140/RG.2.1.4000.6881

Sánchez P and Pérez P (2008) Método de estimación paramétrica de costos en construcción de viviendas de interés social. Ingeniería 12: 51-59

Reynaga N, González G and Robles J (2013) Análisis de ciclo de vida y ecodiseño para la construcción en México. Universidad Autónoma de San Luis Potosí, México.

Sepúlveda S (2008) Biograma: Metodología para estimar el nivel de desarrollo sostenible de territorios. Instituto Interamericano para la Agricultura, Costa Rica.

CENAPRED (2019). https://www.gob.mx/cenapred/es/articulos/que-es-un-reglamento-de-construccion?idiom=es. Accessed 14 March 2021

SMIE (2021). https://www.smie.org.mx/informacion-tecnica/estados/reglamentos-construccion-san-luis-potosi.php. Accessed 14 March 2021.

American Concrete Institute. Building Code Requirements for Structural Concrete (ACI 318_11) and Commentary. https://www.concrete.org/ Accessed 8 March 2021.

American Society of Civil Engineers. Minimum Design Loads for Buildings and Other Structures ASCE Standard ASCE/SEI 7-10. http://www.asce.org. Accessed 8 March 2021.

CYPE (2019). http://www.cype.es. Accessed 11 April 2019 
CMIC a (2018). http://www.cmic.org.mx/comisiones/tematicas/costosyp/indicadoresbm/inpc.htm. Accessed 13 December 2018

CMIC b (2018). http://www.cmicpuebla.org.mx/secciones/?se=2729. Accessed 10 December 2018

CMIC c (2018).http://www.cmic.org.mx/comisiones/Tematicas/costosyp/Costom2/Bimsa/. Accessed 10 December 2018

Guerrero CD (2019) Análisis técnico y económico del diseño por desempeño de edificios con estructura de acero utilizando arriostramientos concéntricos. Gaceta Técnica. https://doi.org/10.13140/RG.2.2.20052.86409 
Figures

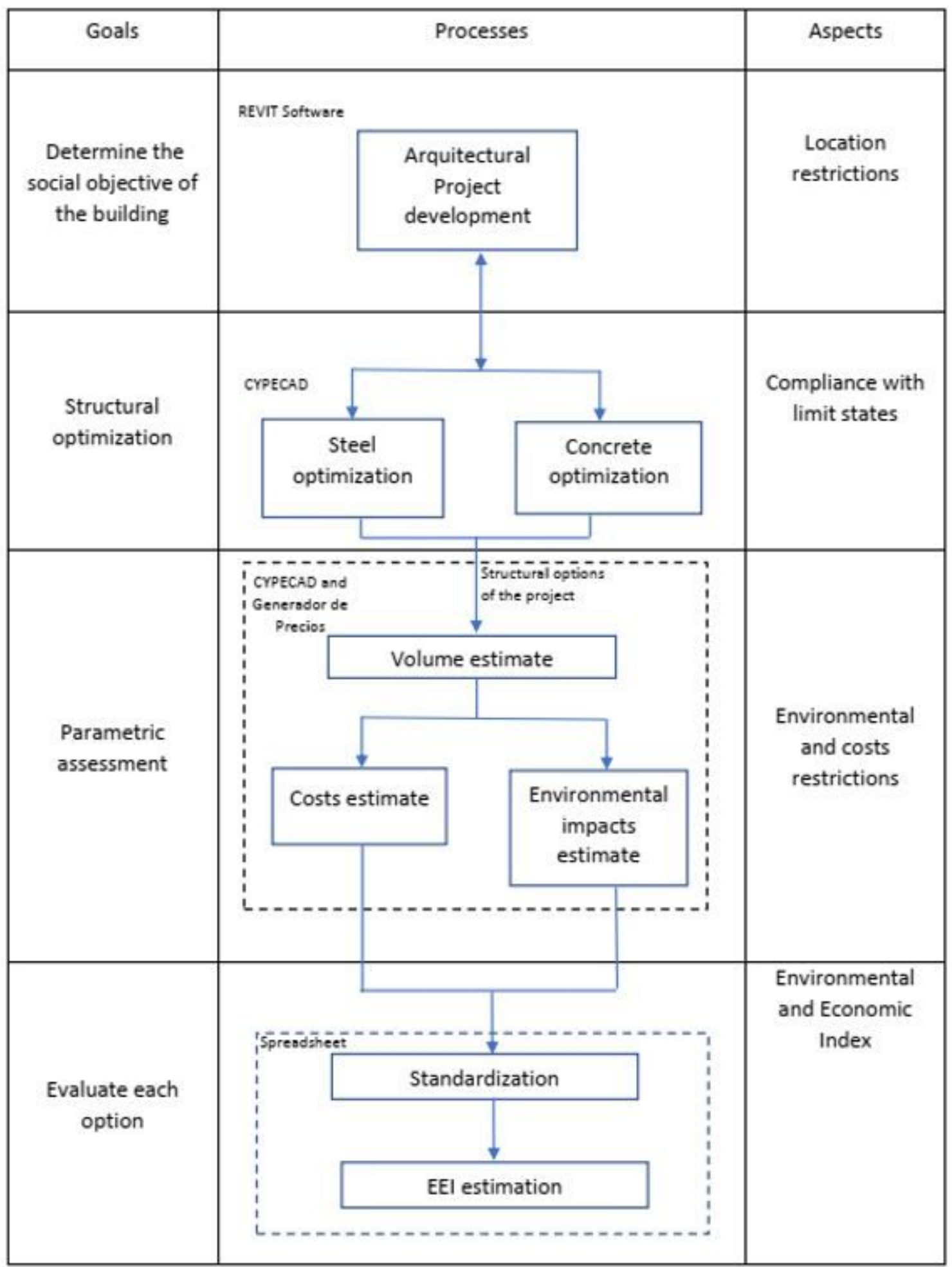

\section{Figure 1}

EEI Method. Source: The authors 


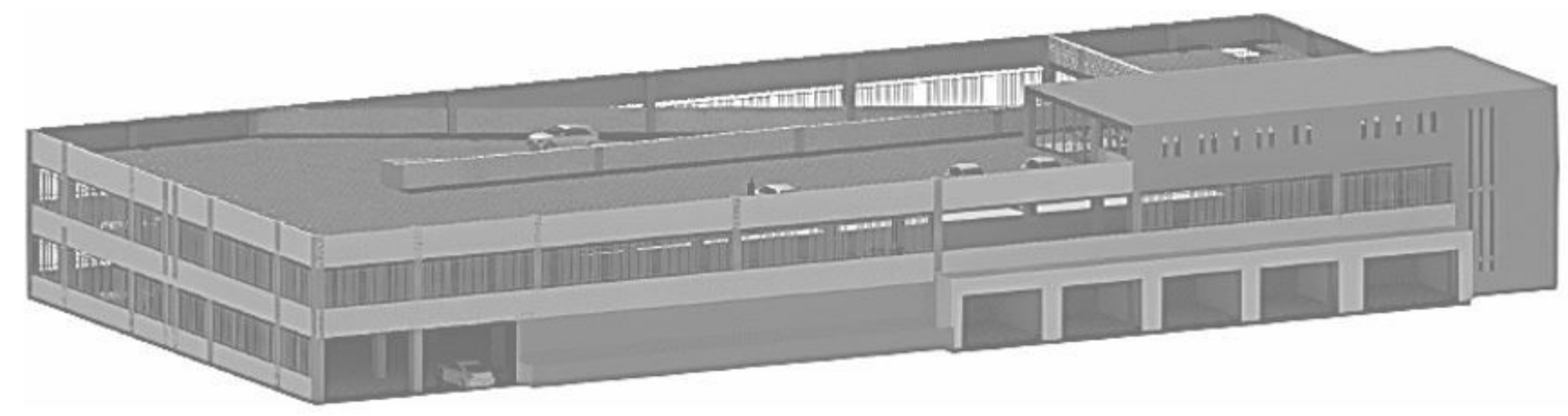

\section{Figure 2}

Architectural model. Source: The authors.

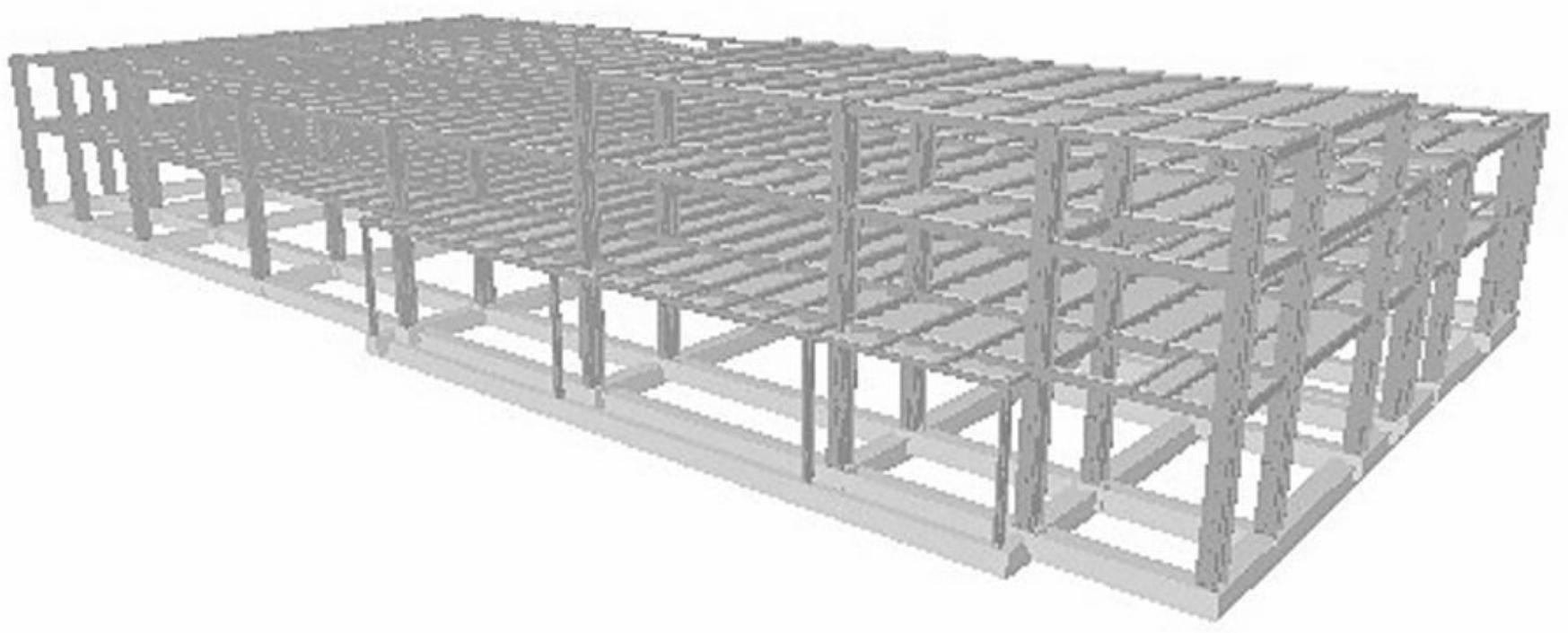

Figure 3

Steel model, with composite columns Source: The authors. 


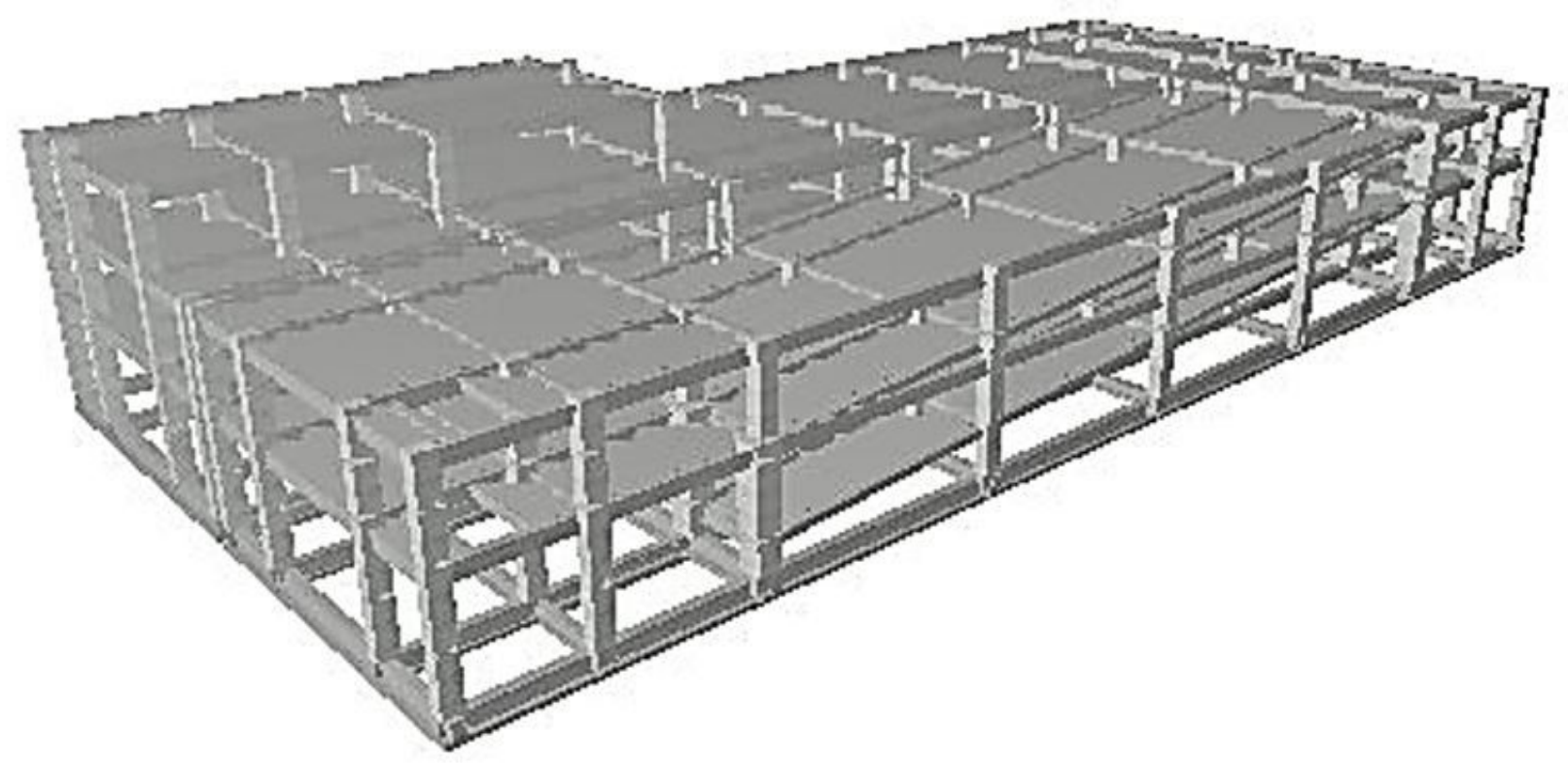

Figure 4

Structural model in reinforced concrete. Source: Own elaboration 
$\$ 3,000$

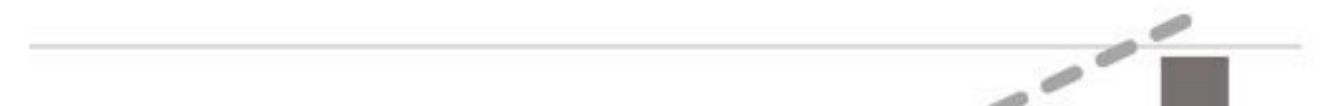

$\$ 2,000$

$\$ 1,000$

$\$ 0$
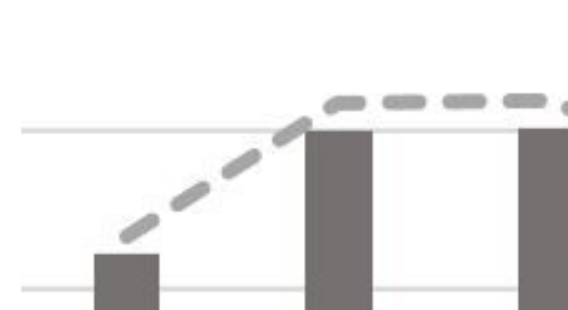

0

\begin{tabular}{|ccc|cc|}
\hline Es_1 & $\begin{array}{c}\text { Es_2 } \\
\text { Sin sismo }\end{array}$ & Es_3 & Es_1S & $\begin{array}{c}\text { Es_2S } \\
\text { Cs_3S }\end{array}$ \\
& & \multicolumn{3}{|c|}{ Con sismo }
\end{tabular}

$0 \%$

$200 \%$

$100 \%$

$$
\text { Costo }---\cdot \text { Porcentaje }
$$

Figure 5

Direct building costs (m2) Source: The authors. 


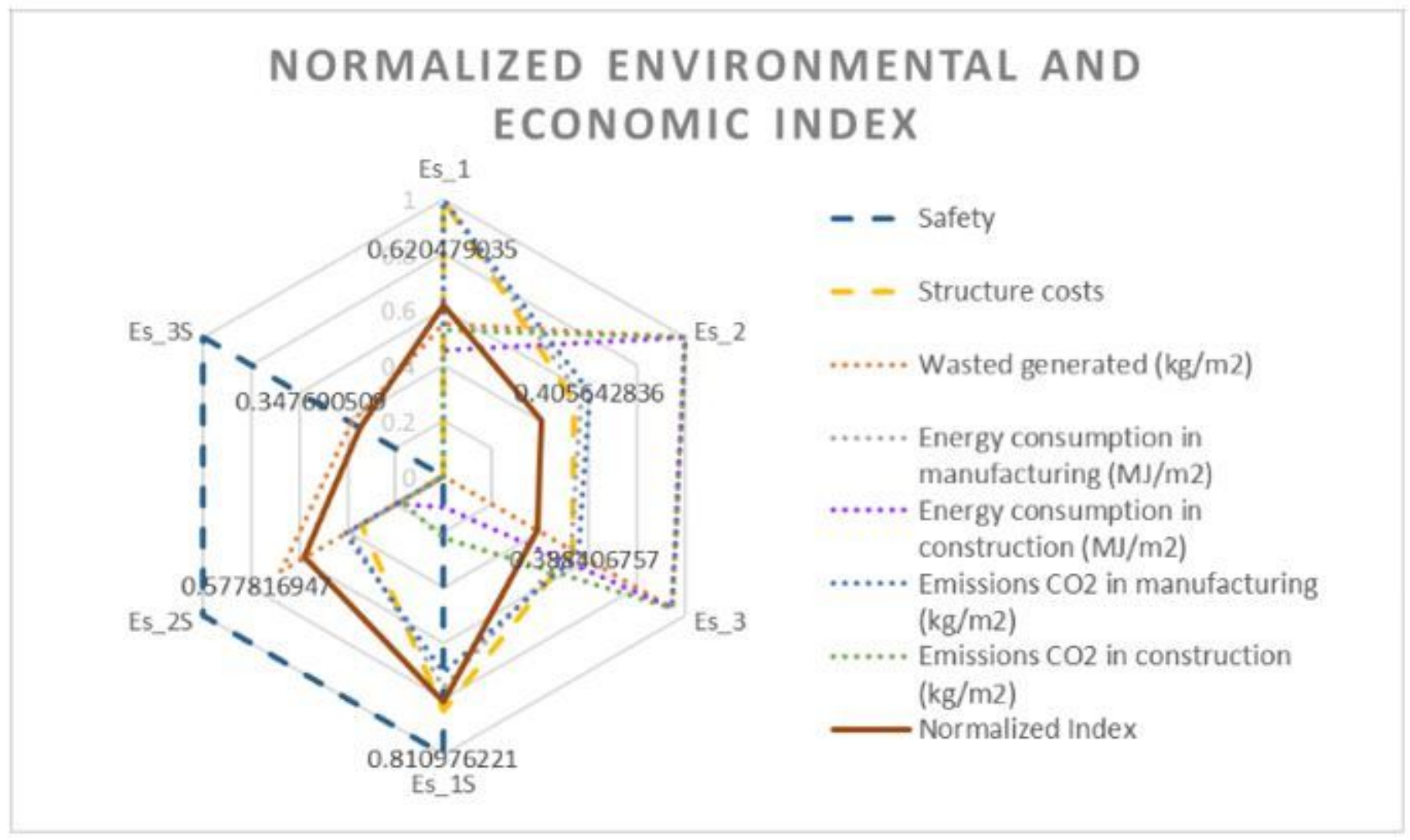

Figure 6

EEl, including phase A-4. Source: The authors. 


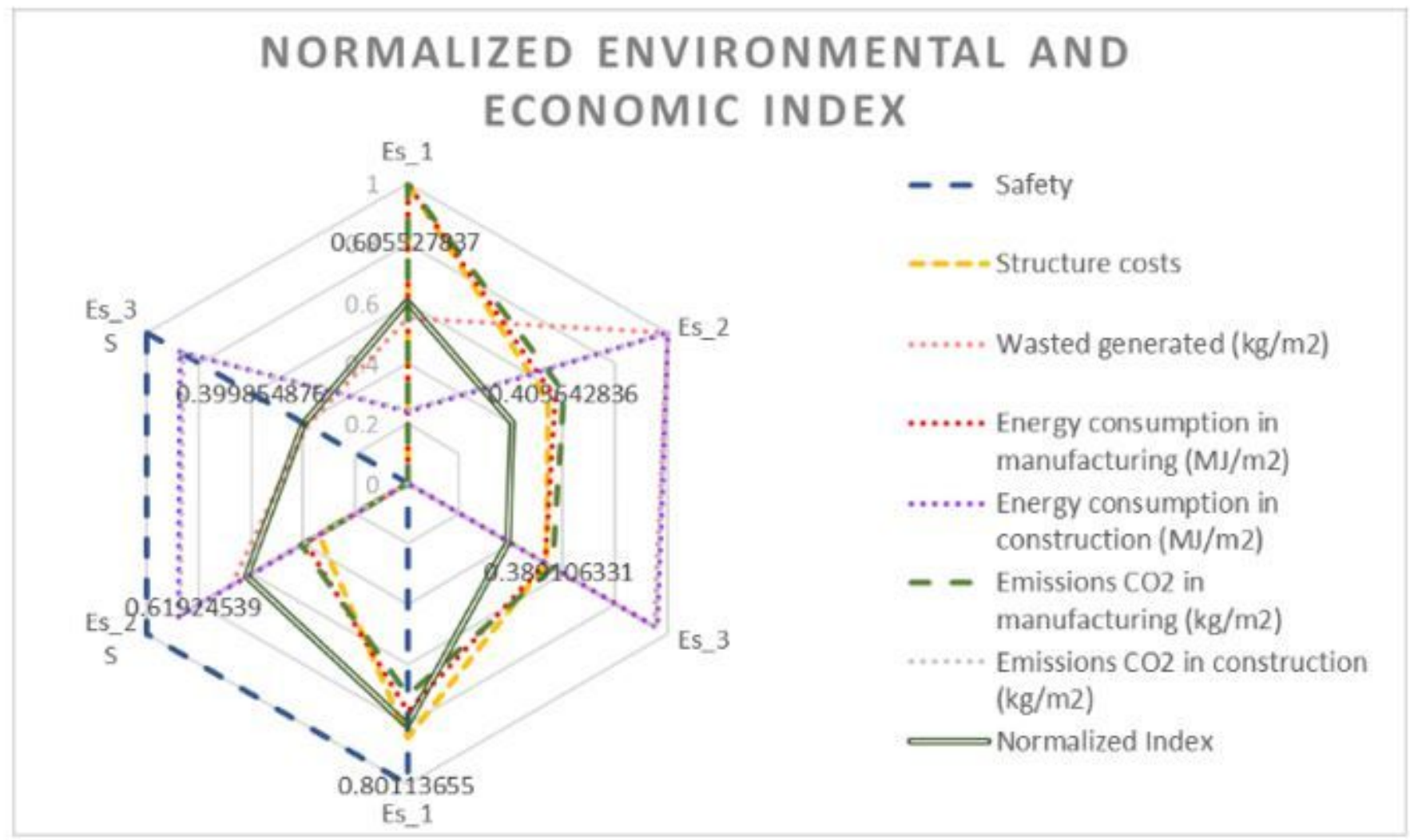

Figure 7

Environmental and Economic Index (without phase A-4). Source: The authors.

\section{Supplementary Files}

This is a list of supplementary files associated with this preprint. Click to download.

- ga.jpg 